\title{
ACQUISITION OF THE INFLECTIONAL MORPHOLOGY OF ENGLISH AS A FOREIGN LANGUAGE: AN ERROR ANALYSIS APPROACH
}

\author{
Emad M. Al-Saidat \\ Al-Hussein Bin Talal University, Jordan
}

\begin{abstract}
This paper aims to identify errors committed by Arab learners of English as a foreign language in the area of inflectional morphology. Errors are classified according to their type in comparison with what seems to be correct in the target language. In order to pinpoint the areas of difficulty and find what makes these areas difficult, the researcher classified errors with reference to their sources into intralingual, interlingual, ambiguous and other errors. The paper also aims at finding possible solutions for the difficulties learners encounter when learning a foreign language in general and English language in particular in a way that would help teachers overcome such difficulties when teaching English to Arab students. It concludes that learners' mother tongue plays a minor role as the interlingual errors constitute less than $25 \%$ of the total number of learner errors; whereas, other factors such as overgeneralization and learning strategies play a major role in learning a foreign language as far as this sample is concerned.
\end{abstract}

Key words: inflectional morphology, second language acquisition, error analysis, Arab learners

\section{INTRODUCTION}

\subsection{Background of the Study}

Learning a language involves a number of steps; the most difficult one is the first step because a language is a complex system of abstract segments and one has to devote a good amount of time to learn such system whether as a first language (L1 henceforth) or a second language (L2 henceforth). Learning of L1 is natural as it is acquired but learning an L2 is artificial as it is learned. In acquiring L1, the native speaker's mind focuses on understanding only one linguistic system as helshe is exposed to it all the time. The acquisition

*E-mail: dresaidat@gmail.com 
process is normal if it is compared to L2 learning process which is more difficult as the learner is exposed to different system of features.

The field of error analysis in second language acquisition was established in the 1970s as an alternative to contrastive analysis. Error analysis is an approach that is applied in linguistics to predict areas of great difficulties for second language learners by using a formal distinction between the learner's first and target languages. However, contrastive analysis was unable to predict a number of errors in many difficult areas in which errors are expected. Thus, Error Analysis is an important instrument in first and second language learninglacquisition research. It sheds the light on the fact that learner's errors reflect a gap in their competence, order of acquisition and accuracy order of learning. The intralingual and interlingual factors determine the source of errors. The former involves difficulties faced by the learner because of different linguistic features of L2 itself; however, the latter involves the direct influence of L1 structures and other features on L2.

Corder (1967:167) argues that "a learner's errors are significant in that they provide to the researcher evidence of how language is learned or acquired, what strategies or procedures the learner is employing in the discovery of the language". He meant to say that the role of errors in teaching and learning any language is significant in linguistics. Learner's errors are significant in three different ways: (i) for the teacher, (ii) the researcher, and (iii) the learner.

Despite the shortcomings of methodology found in this approach, it is still of great significance in research as it has made a significant contribution to the study of second language acquisition and learning because, ultimately, it benefits the learners to identify mistakes committed in a way that the contrastive analysis hypothesis failed to do in the 1960s.

\subsection{Literature Review}

A considerable amount of research has been done on errors committed by Arab learners who study English as a second language. For instance, Abdul Haq (1982) states that writing skill is a linguistic area in which learners tend to commit errors. Mukattash (1983:1 and 169) views the situation in a different way; he described it as a kind of fossilization in which Arab learners of English continue to commit errors in phonology, spelling, morphology and syntax, and they are unable to express themselves comfortably and efficiently. Wahba (1998:36) focuses in his study on errors made by Egyptian learners of English as a second language and concluded that errors are attributed to interlingual as well as intralingual factors simultaneously. Rababah (2000) discusses the language learning difficulties specific to English major and graduate at the Arab world universities focusing on Jordanian students, and he concluded that Arab learners face a number of difficulties in all language skills. Khuwaileh, and Shoumali (2000) examine written errors made by 
Jordanian students in both Arabic and English. According to them, learners made different types of errors including lack of (i) cohesion, (ii) and coherence, and (iii) tense errors. Zughoul (2002) states that Jordanian students who learn English at schools and other educational institutions tend to commit serious errors in the choice of lexical items and in their articulation in the process of communication in day to day conversations. Bataineh (2005) identifies different types of errors in the use of the indefinite article use while analyzing the written composition of a number of Jordanian English language students. She states that among all types of errors identified only the deletion of the indefinite article could be attributed to the mother tongue interference. Analyzing the pronunciation errors experienced by five Saudi learners of English as a second language, Binturki (2008) investigates the difficulties in producing the voiceless bilabial stop /p/, the voiced labiodental fricative $/ \mathrm{v} /$, and the alveolar approximant $/ \diamond /$ especially what word environments were most difficult for participants. His results show that participants had difficulty with the three targeted consonants, but the greatest is with / $/$. The study also found that difficulty was closely related to certain word positions, so all the three sounds were used more accurately when occurring in word initial position than in word final position.

Error analysis has been used also to investigate learners' interlanguage in regions other than the Arab World; for instance, Akande (2003) investigates the acquisition of inflectional morphemes by Yoruba learners of English (a Kwa language spoken from Ivory Coast to Nigeria). The author focuses on the occurrences of these morphemes as well as the errors in their uses. It is found that there is a wide gap in the mastery of the inflectional morphemes, so participants were familiar with only the past tense and the plural morphemes. In addition, errors of omission of -ed, -en, and 3rd person singular marker, and wrong insertion of the past tense inflection were found. The study reveals that learners' mother tongue language interferes with their use of inflectional morphemes of English. In a longitudinal study, Jia and Fuse (2007) investigate the acquisition of certain English grammatical morphemes by native Mandarin-speaking children and adolescents in the United States (arrived in the United States between five and 16 years of age). The goals were to compare the acquisition processes and level of mastery of grammatical morphemes, and identify when age-related differences emerged. The authors choose the regular and irregular past tense morphemes, $3^{\text {rd }}$ person singular morpheme, progressive aspect -ing, copula BE, and auxiliary DO. Results indicate that children with early arrivals achieving greater proficiency than late arrivals in $3^{\text {rd }}$ person singular and regular past tense. Another finding is that language environment is a stronger predictor of individual differences than age of arrival. In the Indian context, Narayanan, Nair and Iyyappan (2008) examine the errors in written English made by 408 first year students of engineering and technology. They find that most of the errors were caused by an over-application of L2, whereas learners' L1 transfer was minor. 
Another study has been conducted by Khansir (2008) who investigates the syntactic errors in English made by 100 college students. He focuses on three features (i) auxiliary verbs, (ii) passive, and (iii) tenses. He finds that all errors committed in these areas are attributed to the learning strategies adopted by participants. The study of error analysis and inflectional morphology has been of a great interest for researchers in different regions (Pervaiz \& Khan 2010; Qaid \& Ramamoorthy 2011a and b; Saeed \& Fatihi 2011, among others).

\section{OBJECTIVES AND METHODOLOGY}

This study is meant to analyze in details the morphological errors produced by the selected sample at The World Islamic Sciences \& Education University for the academic year 2010-2011 in which English is taught as a foreign language. The sample consists of 60 Jordanian students who are specialized in different courses other than English language, but they are studying English as a university obligatory requirement.

The objective of this work is to explicate the morphological errors committed by learners of English as a second language in The World Islamic Sciences \& Education University in Jordan. The researcher tries to find out solutions to the committed errors in the area of inflectional morphology. To account for such errors, a paragraph was given to the students to write and a 45 minute time was given in order to complete the writing task. The researcher hopes that this kind of empirical work will contribute to the understanding of English in a better manner to pave the way for a bright future in the field of research. Therefore, the following questions are posited:

1) What are the types of errors committed by learners in the area of inflectional morphology?

2) What are the sources of these errors?

3) What is the degree of influence that L1 has on L2?

4) How to overcome the difficulties learners have when learning an L2?

\section{DISCUSSION AND RESULTS}

\subsection{Types of Errors}

Participants committed a variety of deviant structures in using inflectional affixes. The researcher has called these deviant structures 'errors' since their occurrence is systematic. Dulay, Burt and Krashen (1982) have introduced the surface structure taxonomy (SST); the general way the learner's sentences look different from what seems to be correct in the target language. It is generally preferred to use the clause "what seems to be correct in the target language' rather than 'the target language sentence' for the reason that in many cases a learner's sentence is vague and can be corrected in different 


\section{VOLUME 5}

ways; thus, more than one target language form is possible. In this study the researcher depends heavily on the context to decide about what seems to be correct in the target language.

Errors committed in the area of inflectional morphology are classified with reference to their types according to SST.

\subsubsection{Omission}

Omission is the absence of an element that its presence is necessary for the grammaticality of the structure. Participants have omitted a number of inflectional morphemes of the following types:

\subsubsection{Plural Morpheme Omission}

In certain contexts, the plural morpheme $\{\mathrm{s}\}$ has been dropped whether it is regular as in (1) or irregular as in (3).

1) *I like sing song.

2) 'I like to sing songs.'

3) *I want have two child

4) 'I want to have two children.'

In (1), the error is committed as the regular plural morpheme $\{s\}$ is omitted at the end of the noun phrase (NP) 'song'. The sentence can be made correct if it is added and the infinitive marker 'to' is also inserted because the verb 'like' subcategorizes an inflectional phrase (IP) as its internal complement. However, in (3), the learner is not aware that the plural morpheme is to inflect the infix in the NP 'child' to become 'children' as in (4).

\subsubsection{Third person singular present tense morpheme}

This is a kind of semi systematic mechanism in the omission of the third person present tense morpheme $\{s\}$ at the end of the imperfective verb is governed by the linguistic context. For instance, in a sentence, the subject and the verb are separated by an adverbial adjunct; thus, learners misuse the inflectional morpheme of the third person present tense marker as (5) and (7).

5) *my father always tell me to be a doctor

6) 'My father always tells me to be a doctor.'

7) because my father sometimes work there

8) 'Because my father sometimes works there.' 
Sentence (5) is wrong due to the omission of the agreement feature $\{s\}$ of the third person singular. The confusion may happen due to the intermediate occurrence of the adverbial adjunct 'always' that ends in the same phoneme between the subject 'my father' and the verb 'tell'. Similar sentences in which the same error has happened is the dependant clauses in (7).

\subsubsection{Past tense morpheme}

The past tense regular morpheme $\{\mathrm{ed}\}$ is omitted in a number of situations as in (9) in which case the verbs are regular in morphology.

9) *I ate the lunch and clean my plate yesterday

10) 'I ate the lunch and cleaned my plate yesterday.'

As the verb 'clean' of the conjoint lacks the $\{\mathrm{ed}\}$ form in (9), the structure is ungrammatical. The syntactic fault might have happened as the learner is unaware of the fact that the verb 'ate' is the correct past tense form of the irregular 'eat'. (10) is made correct as the morpheme is added.

However, in (11), the error is committed as the learner does not neither write the regular from 'dreamed' nor the irregular form 'dreamt' as the verb in question bears the two forms.

11) *when I was in second grade I dream doctor

12) 'When I was in second grade, I dreamed to be a doctor.'

Thus, such errors are also regarded intralingual ones as the learner needs more knowledge of past tense morphology of the English verbs.

\subsubsection{Past Participle Morpheme}

The past participle morpheme $\{\mathrm{en}\}$ as an inflectional affix is omitted. It is obvious that all the structures in which the past participle marker is omitted are found in the perfective type form of the verb; whereas, it is retained in certain passive verb phrases. The process indicates that the passive morpheme is acquired by the learners faster than the perfect in this sample.

13) I have speak with my teacher

14) 'I have spoken to my teacher.'

In (13), the past participle $\{\mathrm{en}\}$ is missing from the verb 'speak' though the perfective marker 'have' is given by the learner. Once it is added, the sentence is good as in (14). 


\subsubsection{Present Participle Morpheme}

The inflectional suffix $\{$ ing $\}$ at the end of a verb is omitted in a number of instances though the indicator is obvious in them as in example (15).

15) I am live beautiful ...

16) 'I am living in a beautiful ...'

The suffix of the present participle $\{$ ing $\}$ is not found at the end of the verb 'live' in (15); hence, the structure is incorrect. The learner does not know that if the auxiliary 'am' is overt, the addition of \{ing $\}$ is a must at the end of the provided verb as in (16) done by the researcher.

Since the learner's mother tongue does not have such morphemes, the errors of these types take place while writing or correcting English as a second language.

\subsubsection{Addition}

Different types of errors are committed by learners by adding an unnecessary affix which makes the structure ungrammatical. This addition is of three types: (i) double marking, (ii) regularization and (iii) simple addition.

\subsubsection{Double marking}

It refers to a situation in which a marker of a feature is erroneously added to a form which is already marked for that feature. In (17), the plural marker $\{s\}$ is added to an NP which is already in the plural form; in such case, the NP in question is double marked and the process amounts the ungrammaticality of the structure.

17) *They want to repair their teeths

18) 'They want to repair their teeth.'

(17) is wrong because the NP 'teeths' is double marked; one for being an irregular plural that carries irregular morpheme and the other is the attachment of the plural $\{\mathrm{s}\}$. (18) is made correct once the plural $\{\mathrm{s}\}$ is deleted.

Not only NPs but also VPs are also double marked by the learners of the selected sample. This fact is visible in a structure in which the third person singular morpheme $\{s\}$ is added to a verb as in (19) and the past tense morpheme (ed) is also added to the past form of the irregular verb as in (21) and in the presence of the past auxiliary with irregular verb as in (25).

19) My father he doesn't speaks English

20) 'My father $\backslash$ He doesn't speak English.' 
The verb 'speaks' is marked by the third person singular marker $\{\mathrm{s}\}$ though it is preceded by the auxiliary 'does' which is marked correctly by the same marker. If the marker $\{\mathrm{s}\}$ is omitted form the verb, the sentence renders correct as in (20); however, this marker is retained with the helping verb in the learner's sentence (19).

21) My three sister tooked me

22) 'My three sisters took me.'

23) She cutted flower and tooked it.

24) 'She cut the flower and took it.'

However, the situation is different with (21) and (23) in which case the past irregular verbs 'tooked' and 'cutted' are overtly marked by \{ed\} which amounts repetition. The only way to make the sentences correct is to omit the past morpheme as in (22) and (24) respectively.

25) I did went to my grandfather's house

26) 'I went to my grandfather's house.'

27) 'I did go to my grand father's house.'

As compared to (19), (25) is ungrammatical due to the double marking of the verb 'went'; the overt occurrence of 'did' in retaining the same form is bad. The possible ways to make the sentence correct is either to delete the auxiliary as in (26) or retain it and reduce the verb 'went' to the base from as in (27).

In short, double marking errors took place due to lack of awareness of the grammatical rules of English from the learner's point of view. In such case, if a verb is in the present or past and proceeded by an auxiliary marked by the singular marker or the past markers, no other part of the verb phrase should be marked as is restricted to the former as rule of English. Likewise, if a verb is in the past in the irregular form, it cannot be marked by the regular marker $\{$ ed $\}$ in any way. English cannot bear double marking in tense.

\subsubsection{Regularization}

Regularization addition refers to the situation where a regular morpheme is added to a word that has a zero morpheme which results in error. In the following case (28) the learner adds the regular past tense marker $\{$ ed $\}$ to a verb that has a zero past tense marker. Regularizing such verb leads to ungrammaticality of the structure.

28) *She cutted flower and tooked it

29) 'She cut the flower and took it.' 


\subsubsection{Simple addition}

If the error of addition is neither due to double marking nor to regularization, it is classified as simple addition and usually referred to as the 'grab bag' of additions. Most of the addition errors found are in this type.

These kinds of errors are committed when the learners try to add the regular plural morpheme to an NP that is not needed at all as in (30).

30) She is my faithfully friends.

31) 'She is my faithful friend.'

In (30), the plural morpheme $\{\mathrm{s}\}$ is added to the NP 'friends' in a wrong manner. It disagrees with the primary verb 'is' which is singular. The sentence can be made correct if $\{s\}$ is deleted as in (31).

Learners commit this error not only with regular NPs in the plural but also with NPs that cannot have plural forms at all as in (32).

32) I helped my sister in homeworks

33) 'I helped my sister in homework.'

The NP 'homework' is an uncountable entity that cannot have a plural form thus (32) is ungrammatical. If the NP in question is used in the singular form, the sentences can be made correct as in (33).

In short, the plural morpheme $\{\mathrm{s}\}$ cannot be attached to NPs preceded by a singular determiner like 'a(n)' or to NPs that cannot be made plural.

The learners add the third person singular marker to a verb whose subject is in the plural form as in (34).

34) My parents decides we lives in Amman...

35) 'My parents decide that we live in Amman...'

The NP 'my parents', in (34) is in the plural form; thus, it cannot take the s-form as in 'decides'. The learners also do not use the correct from of the verb 'live' in the sub-ordinate clause though the subject of which is plural 'we'. It can be made correct if the $\{s\}$ is deleted from the verbs to agree with the subject in plural as in (35). Similar example of the same error is written in (36).

36) My mother and my father wants me a teacher sciences.

37) 'My mother and my father want me to be a science teacher.' 
Thus, the present morpheme is added haphazardly to any verb whether in the past or in the present since the learner does not know the syntactic rules of agreement of L2.

The past tense morpheme is added randomly in various situations in which case the resulting sentence is wrong as in (38).

38) *I want married businessman.

39) 'I wanted to marry a businessman.'

The regular past morpheme $\{\mathrm{ed}\}$ is added in 'married' in (38) instead of being added to the verb 'want' as it is the main verb of the clause. It is supposed to be added to 'want' which also constituently selects an IP as in (39). Likewise, it is the situation in (40).

40) *I want invented anything

41) 'I wanted to invent anything.'

The learner is unable to realize that $\{$ ed $\}$ can never be added to a verb preceded by the infinitive 'to' as in (42).

42) I have to watched TV and married ...

43) 'I have to watch TV and marry...'

The verb 'watch' in (42) cannot be marked by the past regular morpheme \{ed\}. Likewise, it cannot be attached to the coordinated verb 'married'. (43) is correct as the past tense marker $\{$ ed $\}$ is removed.

Hence, the past morpheme can never be added to an embedded verb in the infinitive from.

The present participle morpheme ing \} is added wrongly to a verb that cannot syntactically accept as in (44).

44) we finding directions

45) 'We will find directions.'

However, the learner adds the morpheme \{ing\} to the verb 'watch' without inserting the auxiliary 'am' that make (46) wrong. Such a fault can be corrected in two ways: either (47) or (48).

46) I watching programmes

47) 'I watch programmes.'

48) 'I am watching programmes.' 
Thus, the \{ing $\}$ morpheme as it represents the present participle form is added only if there is a proper auxiliary that precedes it or in the gerundive form of the verb.

The last simple additive error committed by learners is related to the misconception of using the comparative marker $\{\mathrm{er}\}$ as in (49).

49) *my father have car her color green and she is very biger.

50) 'My father has a car; its color is green, and it is very big.'

In (49), the comparative marker \{er\} is added to the adjective 'biger' but in a wrong style. It cannot be attached to it in the presence of the intensifier 'very'. This is visible when the sentence is made good in (50) in which case the $\{\mathrm{er}\}$ is omitted and other essential corrections are made. A similar error is committed in (51) in which the learner uses the correct comparative style but without completion of the process as in (52).

51) *I like smaller family

52) 'I like a smaller family than a large one.'

Thus, the comparative $\{\mathrm{er}\}$ is added to adjectives only of one or two syllables.

In short, the simple additions errors committed by participants cover: (i) the regular plural marker $\{\mathrm{s}\}$, (ii) the third person singular present marker $\{\mathrm{s}\}$, (iii) the past tense marker, (iv) the \{ing $\}$ present participle marker and (v) the \{er\} comparative adjective marker. All of them are used wrongly and the researcher made the corrections as shown in the analysis.

\subsubsection{Misformation}

Misformation errors prevail in learners' competence of a language. Errors involve the substitution of (i) either an already existing morpheme or (ii) a new wrong formation of a morpheme for the correct one, and in both cases this substitution causes the ungrammaticality of the structure. The errors are classified as the following: (i) regularization, (ii) archi forms, and (iii) alternative forms.

\subsubsection{Regularization}

It is a process in which learners use a regular morpheme in a place of an irregular one. For instance, the plural regular morpheme is used instead of the irregular one as in (53).

53) I will have three childs only

54) 'I will have three children only.' 
In (53), the plural morpheme $\{\mathrm{s}\}$ is attached to the NP 'child' instead of using the actual form of irregular as in 'children' in (54). This kind of error is not only restricted to the plural morpheme but also it occurs with the past regular morpheme $\{\mathrm{ed}\}$ attached to a verb as in (55).

$$
\begin{aligned}
& \text { 55) I took ... I sleeped } \\
& \text { 56) 'I took ... I slept.' }
\end{aligned}
$$

It is evident that the verb 'sleep' is an irregular verb and cannot be marked by the regular morpheme $\{\mathrm{ed}\}$ and thus the sentence is ungrammatical as in (55). It is also clear that in (55) the learner is unable to distinguish between regular and irregular verbs and thus slhe treated the verb 'take' as irregular. (56) is correct as both of them written irregular.

Thus, the regular morpheme $\{\mathrm{ed}\}$ can never be added to irregular verbs as they constitute a pattern in the past form of the verb which do not follow the regular pattern of English. This kind of error is regarded interlingual as the learner lacks the knowledge of categorizing the verbs of English into two parts.

The past participle morpheme $\{$ en $\}$ is also added wrongly to a verb in English in the presence of the perfect auxiliary as in (57).

57) She has leaved me alone

58) 'She has left me alone.'

Sentence (57) is incorrect as the verb 'leaved' is treated regular though it is preceded by the perfective marker 'has'. This sentence can be made correct if the past participle form of the verb 'left' is written as in (58).

\subsubsection{Archi\Alternative Forms}

These two types of misformation errors are grouped in one as the errors intermingled in both types. For instance, the learner uses one form of a verb to represent all other forms as in 'speak'; for 'speak', 'speaks', 'spoke', 'spoken', and 'speaking'. So, in this analysis, the second and third types are grouped together since it is not clear from the data available whether the error belongs to either type. However, any misformation error that is not regularization is categorized as archilalternative forms.

The third person singular present tense morpheme $\{\mathrm{s}\}$ is dropped and instead, the past morpheme $\{$ ed $\}$ is used as in (59).

59) I think it suited I

60) 'I think it suits me.' 
In (59), the learner uses the past tense regular morpheme $\{$ ed $\}$ at the end of the verb 'suit' that cause the ungrammaticality of the structure. If the morpheme $\{s\}$ is used instead, it will result in the correctness of the sentence as in (60).

Furthermore, the past tense morpheme is missed and substituted by the present participle morpheme $\{$ ing $\}$ as in (61).

61) I cleaned my home watching TV

62) 'I cleaned my home and watched TV.'

In (61), the learner substitutes the present participle morpheme \{ing\} for the past tense regular morpheme $\{\mathrm{ed}\}$ which makes the structure ungrammatical. If the substitution is altered, the result will be grammatical as in (62).

In short, errors of this type seem to be random in what substitutes what as in (59), the learner substitutes $\{\mathrm{ed}\}$ for $\{\mathrm{s}\}$ while in (61) slhe substitutes $\{$ ing $\}$ for $\{$ ed $\}$. Thus, it can be said that the occurrence of these errors is not governed by any rule.

\subsection{Sources of Errors}

In the past, it was believed that most language errors were caused by transfer of features from one language to the target language. Later, according to Richards (1971), it was found that the influence of native language on the new language is quite minimal; that is, it affects only $3-25 \%$ of such errors.

Following the comparative taxonomy for the classification of errors proposed by Dulay, Burt and Krashen (1982:163-172), four major sources are identified: developmental, interlingual, ambiguous, and other.

\subsubsection{Developmental Intralingual Errors}

Developmental errors include learners' own strategy in learning a language. They are committed by most learners of a language regardless of their mother tongue languages so; this is evidence in some way to say that there is a sense of universality in these errors (Ellis, 1994). It is a learning strategy adopted by learners of whether learning L1 or an L2 to be able to communicate especially in their beginning stages. Learners unintentionally omit grammatical morphemes rather than lexical ones since the latter carry the meaning of the message, and overgeneralize certain rules in order to ease learning and simplify communication. It is generally felt by learners that one has to make and understand messages, so the question of grammaticality comes in advanced stages.

Overgeneralization errors are caused by the rules of the target language itself. In this process learners apply a rule in places where it doesn't apply as 
when the English regular plural morpheme is used in a noun that has an irregular one, for example, 'man' is pluralized as 'mans' resulting in error for which the mother tongue language has no role to play. Such errors are referred to as intralingual errors. In later stages learners overcome such difficulties as a result of gaining more information about the way target language works and developing their competence. Errors attributed to the learner's stage of development are called 'developmental errors'. Most of the developmental errors found in the available date are of the omission and overgeneralization types, however a few errors are found to be of the addition and misformation types of errors.

Learners use the singular form instead of the plural one; as a result, the structure will be incorrect as in (63), (65) and (67) if the singular form is replaced by the plural one, the structure will be grammatical as in (64), (66) and (68) respectively.

63) *whatever these problem ...

64) 'Whatever these problems...'

65) *I have got three brother and two sister

66) 'I have got three brothers and two sisters.'

67) *I will have three boy and two girl

68) 'I will have three boys and two girls.'

Learners use singular form of a verb with a plural subject as in (69). If the plural form of the verb is used, the sentence will be grammatical as in (70).

69) *hobbies is reading and play tennis ...

70) 'Hobbies are reading and playing tennis.'

Learners in beginning stages overgeneralize some of the features they have learned. For example, the third person singular present tense morpheme $\{\mathrm{s}\}$ is used in wrong places sometimes instead of the past tense morpheme as in (71) or added to past tense or base forms as in (73) and (75) respectively. If the correct form of the verb is used, the structure will be grammatical as in (72), (74) and (76) respectively.

71) *my parents decides we lives in Amman

72) 'My parents decided that we live in Amman.'

73) * my brother tolds me that ...

74) 'My brother told me that ...'

75) *I don't know I changes this dream...

76) 'I don't know I will change this dream...'

One of the dominant communicative strategies used by language learners in general is the omission of grammatical morphemes. In (77) learners omit 


\section{VOLUME 5}

the third person singular present tense morpheme; a process that makes the structure ungrammatical. Adding the missing morpheme makes the structure grammatical as illustrated in (78).

77) *my father always tell me be doctor

78) 'My father always tells me be a doctor.'

In (79) the learner makes wrong subject-verb agreement. A third person singular subject must have a singular verb form; if 'has' is used instead of 'have', the structure will be grammatical as in (80).

79) *my father have car...

80) 'My father has a car...'

The regular past tense morpheme is used instead of the irregular one as in (81) and (83). This regularization process makes the structure ungrammatical. It is avoided in (82) and (84).

81) *my three sister taked me ...

82) 'My three sisters took me ...'

83) *my boat sinked so I had to ...

84) 'My bout sank so I had to ...'

In (85), learners use the present tense form instead of the past one which results in ungrammatical structure. If the past tense form is used instead, the structure will be grammatical as in (86).

85) *when I was at the middle of the sea a shark come

86) 'When I was at the middle of the sea a shark came.'

In (87) the past form 'thought' is used instead of the present one 'think' which results in error. If the present form is used as in (88), the structure will be grammatical.

87) *I shall thought to job...

88) 'I shall think about a job...'

Learners apply a feature to forms where it doesn't apply. This overgeneralization process makes the structure ungrammatical as in (89) in which the plural $\{s\}$ is added to a noun that has an irregular plural. If $\{s\}$ is omitted; the structure will be grammatical as in (90).

89) *they want to repair their teeths 
90) 'They want to repair their teeth.'

Learners use the adjectival suffix $\{\mathrm{er}\}$ in a wrong place as in (91) which makes the structure incorrect. If this suffix is omitted as in (92), the structure will be grammatical.

91) *I like the smaller family

92) 'I like the small family.'

\subsubsection{Interlingual Errors}

These kinds of errors are influenced by the learners' native language which interferes with target language learning. Most learners translate word by word idiomatic expressions, vocabulary and even the grammatical rules of the learners' first language into the second language. This process could be positive in a case if the L1 feature already exists in the target language which is known as 'positive transfer'; whereas, it is 'negative transfer' if the learner uses an L1 feature in the target language and this feature is not similar or doesn't exist at all in the target language. Negative transfer is aslo referred to as 'interference'. In contrastive analysis, it is believed that the type of errors made by the learners of the target language can be predicted and their causes can be determined in order to prevent and eliminate these errors. Richards (1971) has given the following figures: Between 3-25 per cent of all errors are errors of mother tongue influence and 75 per cent of errors are 'noncontrastive' errors. That is to say the majority of errors have nothing to do with learners' mother tongue language.

The two verb forms 'past tense' and 'past' participle are represented by one form in learners' mother tongue language; a fact that influences learning process which makes the structure ungrammatical as in (93). If the correct verb form is used as in (94), the structure will be grammatical.

93) *The man I seen him yesterday

94) 'The man I saw yesterday.'

\subsubsection{Ambiguous Errors}

Ambiguous errors are those which can be attributed to both mother tongue language interference and target language at the same time; as a result, they can be classified as interlingual and as developmental ones too.

In Arabic language, the noun 'homework' has a plural form unlike English language where it is uncountable. In (95) learners add the plural $\{\mathrm{s}\}$ to the noun 'homework' as a result of L1 transfer or as a result of overgeneralization which is purely developmental reason which in both cases 
results in error. If the plural $\{\mathrm{s}\}$ is not attached, the structure will be grammatical as in (96).

95) *I helped my sister in homeworks

96) 'I helped my sister in homework.'

Present simple and present progressive are represented by one form in learners' native language that is why they alternate them sometimes. This process could be attributed to learners' stage of development which results in ungrammaticality as in (97) where 'live' is used instead of 'living'. Supplying the correct form makes the structure grammatical as in (98).

97) *I like live in foreigner country.

98) I like living in a foreign country.

\subsubsection{Other Errors}

This category covers learners' errors that cannot be attributed to L1 or L2. However, two cases are mentioned below.

Learners use the $\{\mathrm{ed}\}$ form in situations where it must not be used which results in ungrammatical structure as in (99). If the correct form is used as in (100), the structure will be grammatical.

99) *we took the rope to fixed...

100) 'We took the rope to fix...'

The presence of the $\{\mathrm{ing}\}$ form instead of the other verb forms in (101) is ungrammatical. If the correct verb from is used instead, the structure will be grammatical as in (102).

101) *In the past my uncle suggestion me working baby sitting

102) 'In the past my uncle suggested me to work as a babysitter.'

\section{CONCLUSION}

It can be concluded here that there is a kind of universality in the way learners learn English language as an L2 since these findings are similar to those of Corder (1967); Bataineh (2005); Narayanan, Nair and Iyyappan (2008), and Khansir (2008). The evidence for the universality in acquiring L2 is omission of the plural morpheme whether regular or irregular as in (1), (3), (63), (65) and (67) and the omission of the third person singular, $\{$-ed $\}$ and $\{-$ en) morphemes which is also common among learners regardless of their mother tongues as found in the literature (see Akande, 2003). 
Learner's language is variable and such variability is somehow systematic. It is found in this study that this systematicity is governed by the linguistic context as in (5) and (7) where the subject and the verb are separated by an adverbial the agreement is lost; whereas in other cases, it is retained.

Learners follow an unintentional definite order when acquiring a language, for example, participants acquire irregular forms before irregular ones. Evidence comes from the use of the past tense morpheme as in (9) and (11). Another example is the domination of the present participle over the simple present and the base forms as in (44), (46) and (61).

Participants are careful about the grammar of the target language. In this study, such phenomenon is clear from a few hybrid forms produced as a result of hypercorrection as in (21) and (23).

As clear from the above causes of errors, it is recommended that teachers of Arab students of English present the eight inflectional affixes systematically in which the regular-irregular cases are stressed for nouns and verbs. Comparison of L1 and L2 features is necessary in situations where L1 might interfere since the former is always present in learners' minds as put by Cook (1992:589) who states that "the L1 is present in the L2 learners' minds, whether the teacher wants it to be there or not. The L2 knowledge that is being created in them is connected in all sorts of ways with their L1 knowledge". As a result, it is recommended that when working with L2 learners, teachers must not treat the L2 in isolation from the L1.

\section{REFERENCES}

Abdul Haq, F. (1982). An analysis of syntactic errors in the composition of Jordanian secondary students. Unpublished Master Dissertation. Yarmouk University, Irbid: Jordan.

Akande, A. (2003). Acquisition of the inflectional morphemes by Nigeria learners of English language, Nordic Journal of African Studies, 12(3), 310-326.

Bataineh, R. (2005). Jordanian undergraduate EFL students' errors in the use of the indefinite article. Asian EFL Journal, 7(1), 56-76.

Binturki, T. (2008). Analysis of pronunciation errors of Saudi ESL learners. Unpublished Master Dissertation. Southern Illinois University at Carbondale, Carbondale, Illinois: US A.

Cook, V. (1992). Evidence for multi-competence. Language Learning, 42(4), 557-591.

Corder, S. (1967). The significance of learners' errors. International Review of Applied Linguistics, 5, 161-170.

Dulay, H., Burt, M. \& Krashen, S. (1982). Language two. Oxford: Oxford University Press. 
Ellis, R. (1994). The study of second language acquisition. Oxford: Oxford University Press.

Jia, G. \& Fuse, A. (2007). Acquisition of English grammatical morphology by native Mandarin-speaking children and adolescents: age-related differences. Journal of Speech, Language, and Hearing Research, 50, 1280-1299.

Khansir, A. (2008). Syntactic errors in English committed by Indian undergraduate students. Language in India, 8(7), 94-105.

Khuwaileh, A. \& Shoumali, A. (2000). Writing errors: a study of the writing ability of Arab learners of academic English and Arabic at university. Language, Culture and Curriculum, 13(2), 174-183.

Mukattash, L. (1983). The problem of difficulty in foreign language learning. In E. Dahiyat, \& M. Ibrahim (Eds.), Papers from the first conference on the problems of teaching English language and literature at Arab universities. University of Jordan, Amman: Jordan, 145-175.

Narayanan, R., Nair, N. \& Iyyappan, S. (2008). Errors made by the students of engineering and technology in written English. Language in India, $8(4), 1-9$.

Pervaiz, A. \& Khan, M. (2010). Syntactic errors made by science students at the graduate level in Pakistan - causes and remedies. Language in India, 10(9), 268-284.

Qaid, Y. \& Ramamoorthy, L. (2011a). A study of Arabic interference in Yemeni university students' English writing. Language in India, 11(4), 28-37.

Qaid, Y. \& Ramamoorthy, L. (2011b). Analysis of intralingual errors in learning English as a foreign language by Yemeni students. Language in India, 11(5), 534-545.

Rababah, G. (2000). Communication problems facing Arab learners of English. Journal of Language and Learning, 3(1), 180-197.

Richards, J. (1971). A noncontrastive approach to error analysis. English Language Teaching, 25, 204-219.

Saeed, G. \& Fatihi, A. (2011). A Contrastive analysis of inflectional affixes in English and Arabic. Language in India, 11(5), 76-90.

Wahba, E. (1998). Teaching pronunciation-why?. Language Teaching Forum, 36(3), 3-2.

Zughoul, M. (2002). Interlanguage syntax of Arabic-speaking learners of English: the noun phrase. ERIC Document \#: ED479649, 1-23. 